\title{
Remodeling root repair with an external aortic ring annuloplasty
}

\author{
Emmanuel Lansac, MD, PhD, ${ }^{\mathrm{a}}$ Isabelle Di Centa, MD, ${ }^{\mathrm{b}}$ Ghassan Sleilaty, MD, ${ }^{\mathrm{a}}$ Stephanie Lejeune, MS, ${ }^{\mathrm{a}}$ \\ Alain Berrebi, MD, ${ }^{\mathrm{a}}$ Pavel Zacek, MD, PhD ${ }^{\mathrm{c}}$ and Mathieu Debauchez, $\mathrm{MD}^{\mathrm{a}}$
}

\begin{abstract}
Objective: Although the remodeling technique provides the most dynamic valvesparing root replacement, a dilated annulus $(>25 \mathrm{~mm})$ is a risk factor for failure. Aortic annuloplasty aims to reduce the annulus diameter, thus increasing coaptation height to protect the repair. The results of 177 patients with remodeling and external aortic ring annuloplasty were studied.
\end{abstract}

Methods: Data were collected from the Aortic Valve repair InternATiOnal Registry. Preoperative aortic insufficiency grade 3 or greater was present in 79 patients $(44.7 \%)$. The valve was bicuspid in 59 patients $(33.3 \%)$. External annuloplasty was performed through a homemade Dacron ring (56) or a dedicated expansible aortic ring (121).

Results: Thirty-day mortality was $2.9 \%$ (5). Mean follow-up was $41.1 \pm 36.4$ months. For the whole series, freedom from valve-related reoperation, aortic insufficiency grade 3 or greater, aortic insufficiency grade 2 or greater, and major adverse valve-related events were $89.5 \%, 90.5 \%, 77.4 \%$, and $86.6 \%$ at 7 years, respectively, with similar results for tricuspid and bicuspid valves. Since 2007, systematic use of calibrated expansible ring annuloplasty, followed 1 year later by systematic cusp effective height assessment, significantly increased 7-year freedom from valve-related reoperation, aortic insufficiency grade 3 or greater, and major adverse valve-related events up to $99.1 \% \pm 0.9 \%$ $(P=.017), 100 \%(P=.026)$, and $96.3 \% \pm 1.8 \%(P=.035)$, respectively, whereas freedom from aortic insufficiency grade 2 or greater remained unaffected $(78.1 \% \pm 7.6 \%)$. Calibrated annuloplasty and effective height assessment were identified as protective factors from reoperation: hazard ratio, $0.13 ; 95 \%$ confidence interval, $0.02-1.06 ; P=.057$ and hazard ratio, $0.11 ; 95 \%$ confidence interval, $0.01-0.95 ; P=.044$, respectively.

Conclusions: The standardization of remodeling root repair with calibrated expansible aortic ring annuloplasty and cusp effective height assessment improves valve repair outcomes. (J Thorac Cardiovasc Surg 2017;153:1033-42)

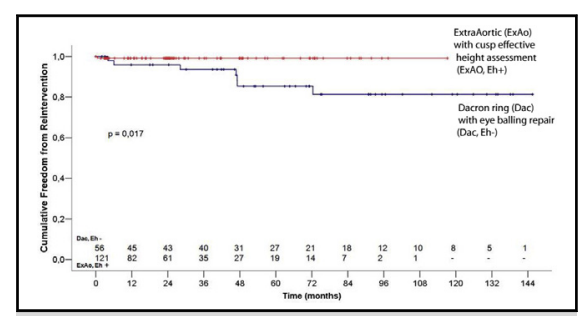

Freedom from reoperation (ExAo + cusp effective height, Dacron ring + eyeballing).

\section{Central Message}

Remodeling with calibrated expansible aortic ring annuloplasty and cusp effective height assessment improves valve repair outcomes.

\section{Perspective}

Standardization of the valve-sparing procedure through remodeling root repair with a calibrated expansible aortic ring annuloplasty and cusp effective height assessment should improve the reproducibility and rate of valve repair, even in severe AI. Because repair of bicuspid valves provides stable results similar to those of tricuspid valves, it may be offered for aneurysm with pliable bicuspid valves.

See Editorial Commentary page 1043.
Recent guidelines on the management of aortic diseases mentioned "aortic annuloplasty" as part of a class I indication: "Aortic valve repair, using the reimplantation technique or the remodeling technique with aortic annuloplasty, is recommended in young patients with aortic

\footnotetext{
From the a Department of Cardiac Pathology, Institut Mutualiste Montsouris, Paris, France; ${ }^{b}$ Vascular Surgery Unit, Hopital Foch, Suresnes, France; and ${ }^{c}$ Department of Cardiac Surgery, Charles University in Prague, Faculty of Medicine and Faculty Hospital, Hradec Kralove, Czech Republic.

The study is sponsored by Assistance Publique Hôpitaux de Paris and supported by a research grant from the French Ministry of Health (Conservative Aortic Valve surgery for aortic Insufficiency and Aneurysm of the Aortic Root trial, PHRC AOR 04038) and the nonprofit Association chirurgicale pour le DEveloppement et l'amélioration des TEchniques de dépistage et de traitement des maladies Cardio-vasculaires.
}

root dilation and tricuspid aortic valves."1 Although the remodeling technique provides physiologic cusp movement within the 3 reconstructed neo-sinuses, thus preserving root expansibility through the interleaflet triangles, an untreated dilated aortic annulus $(>25-28 \mathrm{~mm})$ has been identified as a

\footnotetext{
Read at The American Association for Thoracic Surgery Aortic Symposium 2016 New York, New York, May 12-13, 2016.

Received for publication May 24, 2016; revisions received Nov 25, 2016; accepted for publication Dec 9, 2016; available ahead of print Feb 7, 2017.

Address for reprints: Emmanuel Lansac, MD, PhD, Cardiac Pathology Department, Institut Mutualiste Montsouris, 42 Boulevard Jourdan, 75014 Paris, France (E-mail: emmanuel.lansac@imm.fr). 0022-5223/\$36.00

Copyright (C) 2017 by The American Association for Thoracic Surgery http://dx.doi.org/10.1016/j.jtcvs.2016.12.031
} 


\section{Abbreviations and Acronyms \\ AI $=$ aortic insufficiency \\ AVIATOR $=$ Aortic Valve repair InternATiOnal Registry \\ CI $=$ confidence interval \\ ExAo $=$ expansible aortic ring diameter \\ HR = hazard ratio \\ MAVRE = major adverse valve-related events}

\section{Scanning this QR code will take you to the supplemental videos for the article.}

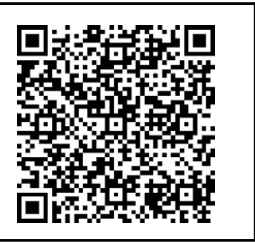

risk factor for failure. ${ }^{2-10}$ Furthermore, most failures with valve-sparing techniques are due to residual cusp prolapse as a primary unrecognized lesion or secondary to an induced prolapse after root reconstruction. ${ }^{11,12}$ As a result, the rate of valve repair remains low and is practiced on highly selected patients, except in a few expert centers. Although more than $80 \%$ of aortic root aneurysm surgeries are undertaken for dystrophic aortic insufficiency (AI) (with tricuspid, bicuspid, or unicuspid valve), a recent analysis of the Society of Thoracic Surgeons database revealed that only $14 \%$ of these patients receive a valve-sparing procedure. ${ }^{13-15}$ This fact brings into question the reproducibility and lack of technical standardization associated with these current procedures.

To address these issues, a standardized aortic valve repair approach addressing both the aorta and the valve was developed, associating a physiologic reconstruction of the aortic root according to the remodeling technique, with cusp effective height resuspension and a subvalvular external aortic ring annuloplasty, which we analyzed in this study. ${ }^{8,16-20}$

\section{MATERIALS AND METHODS \\ Patient Population}

This analysis focuses on all consecutive patients undergoing operation with the remodeling technique associated with an external aortic ring annuloplasty by Dr Lansac (or under his direct proctoring) in the successive centers where he worked, from May 2003 to November 2015, making this study the longest follow-up of the external aortic ring annuloplasty. Patient characteristics and 30-day outcomes are detailed in Table 1. Two patients underwent operation for acute aortic dissection. Preoperative AI grade 3 or greater was present in $44.7 \%$ of patients. Interventions were performed in 4 institutions in France: University Hospital La Pitie Salpetriere, University Hospital Bichat-Claude Bernard, Foch Hospital, and, since 2010, Institut Mutualiste Montsouris. Data were prospectively collected in the multicentric international AorticValve repair InternATiOnal Registry
(AVIATOR), including 35 patients from the Conservative Aortic Valve surgery for aortic Insufficiency and Aneurysm of the Aortic Root trial ${ }^{21}$ (ClinicalTrials.gov identifier: NCT00478803). This study was approved by the institutional review boards for the multicentric AVIATOR (Comité Consultatif sur le Traitement de l'Information en matière de Recherche dans le Domaine de la Santé $\mathrm{n}^{\circ}$ 13,738 Bis) and multicentric Conservative Aortic Valve surgery for aortic Insufficiency and Aneurysm of the Aortic Root trial (Comité de Protection des Personnes Ile de France VI A00362-49). The need for individual patient consent was waived.

\section{Surgical Technique}

All patients underwent the standardized approach to aortic valvesparing root replacement to treat dilation of the aortic annulus $(\geq 25 \mathrm{~mm})$ as measured intraoperatively with the Hegar dilator ${ }^{14}$ (Figure 1). Cusp geometric height was assessed to detect valve retraction, defined as less than $16 \mathrm{~mm}$ for tricuspid cusps and less than $20 \mathrm{~mm}$ for the nonfused cusp in bicuspid valves; these values are considered the cutoff for valve replacement. ${ }^{22}$ After resecting the sinuses of Valsalva, an external dissection of the aortic root is performed down to the aortic annulus. Native aortic annulus diameter is measured with Hegar dilators because it is the sole criterion for selecting the sizes of the aortic ring and the graft used to remodel the aortic root (Gelweave Valsalva; Vascutek Ltd, Glasgow, UK) (Table 2). The expansible aortic ring diameter (ExAo) is undersized by 1 size relative to the measured native annulus diameter: annulus 25 to $27 \mathrm{~mm}$ (ExAo $25 \mathrm{~mm} /$ Valsalva $26 \mathrm{~mm}$ ); annulus 28 to $30 \mathrm{~mm}$ (ExAo 27/Valsalva 28); annulus 31 to $35 \mathrm{~mm}$ (ExAo 29/Valsalva 30); annulus greater than $36 \mathrm{~mm}$ (ExAo 31/Valsalva 32). Six "U” stitches are placed circumferentially from inside-out in the subvalvular plane, below the nadir of each cusp and at the base of each interleaflet triangle, except between the right and noncoronary sinuses, where the sixth stitch is placed externally on the atrium wall at the lowest level of dissection to avoid potential lesion to the bundle of His or membranous septum. The first step of valve repair, done before root reconstruction, consists of aligning the cusp free edges and correcting any excess free margin length through central plicating stitches or cusp resection. Remodeling of the aortic root is standardized by scalloping the Valsalva graft into 3 symmetrical neo-sinuses (placing the commissures at $120^{\circ}$ in tricuspid valves) (Video 1 ) or 2 symmetrical neo-sinuses (placing the commissures at $180^{\circ}$ in bicuspid valves) (Video 2). The heights of the scallops are cut equally up to the transition point between circumferential and axial folds of the graft, thus ensuring that the commissures are placed at the same level. The second step of cusp repair is performed after root reconstruction and consists of assessing cusp effective height with a dedicated cusp caliper (Fehling Instruments, Karlstein, Germany) to evaluate residual or induced cusp prolapse according to the principle of Schäfers and colleagues. ${ }^{23}$ Plicating stitches are added on the free edge of the culprit leaflet until an effective height of $9 \mathrm{~mm}$ is achieved.

The 6 anchoring "U" stitches are passed around the expansible aortic ring, which is seated externally around the remodeled aortic root and tied in the subvalvular position. In earlier experience, the ring was homemade from a slice of a Dacron tube graft and used in 56 patients (31.6\%). Since 2007, a calibrated expansible aortic ring (Extra-Aortic; CORONEO, Inc, Montreal, QC, Canada) has been used (121 patients, $68.4 \%){ }^{19}$

Intraoperative transesophageal echocardiography was performed in all cases. Any residual AI greater than grade 1 mandated reexploration of the aortic valve. Postoperative anticoagulation consisted of aspirin ( $75 \mathrm{mg} / \mathrm{d}$ ) administered for 2 months unless persistent atrial fibrillation presented, in which case oral anticoagulation was used. For all patients, clinical and echocardiographic data were collected and manually entered into the AVIATOR preoperatively and perioperatively, at discharge, and yearly thereafter through patient visits to cardiologists or surgeons or via direct contact with the patient.

Primary end points were all causes and valve-related mortality and reoperation at 30 days and follow-up periods. Secondary end points were the incidence of major adverse valve-related events (MAVRE), defined 
TABLE 1. Patient characteristics

\begin{tabular}{|c|c|c|c|c|}
\hline & Total & Tricuspid & Bicuspid & Unicuspid \\
\hline Sample size & 177 & $112(63.3 \%)$ & $59(33.3 \%)$ & $6(3.4 \%)$ \\
\hline Age, $y$, mean $\pm \mathrm{SD}$ (range) & $50.4 \pm 15.1(15-81)$ & $53.2 \pm 15.0(15-81)$ & $47.3 \pm 13.4(20-74)$ & $47.3 \pm 13.4(20-74)$ \\
\hline$\leq 35 \mathrm{y}$ & $20.0 \%$ & $16.8 \%$ & $22.4 \%$ & - \\
\hline $36-60 y$ & $52.7 \%$ & $47.5 \%$ & $62.1 \%$ & $50 \%$ \\
\hline$>60 \mathrm{y}$ & $27.3 \%$ & $35.6 \%$ & $15.5 \%$ & $50 \%$ \\
\hline Sex ratio $(F / M)$ & $33 / 144(18.6 \%)$ & $22 / 90(19.6 \%)$ & $9 / 50(15.3 \%)$ & $2 / 4(33.3 \%)$ \\
\hline BMI $\left(\mathrm{kg} / \mathrm{m}^{2}\right)$, mean $\pm \mathrm{SD}$ (range) & $25.7 \pm 4.6(15.2-43.7)$ & $25.9 \pm 5.3(15.2-43.7)$ & $25.6 \pm 3.3(20.8-36.1)$ & $25.6 \pm 3.3(20.8-36.1)$ \\
\hline Marfan syndrome & $28(15.8 \%)$ & $26(23.2 \%)$ & $2(3.4 \%)$ & - \\
\hline Turner syndrome & - & - & - & - \\
\hline \multicolumn{5}{|l|}{ NYHA } \\
\hline I & $104(58.7 \%)$ & $63(56.3 \%)$ & $36(61.0 \%)$ & $5(83.3 \%)$ \\
\hline II & $59(33.3 \%)$ & $40(35.7 \%)$ & $19(32.2 \%)$ & - \\
\hline III & $12(6.8 \%)$ & $8(7.1 \%)$ & $3(5.1 \%)$ & $1(16.7 \%)$ \\
\hline IV & $2(1.1 \%)$ & $1(0.9 \%)$ & $1(1.7 \%)$ & - \\
\hline \multicolumn{5}{|l|}{ Preoperative AI grade } \\
\hline 0 & $29(16.4 \%)$ & $18(16.1 \%)$ & $11(18.6 \%)$ & - \\
\hline I & $30(16.9 \%)$ & $19(17.0 \%)$ & $9(15.3 \%)$ & $2(33.3 \%)$ \\
\hline II & $39(22.0 \%)$ & $25(22.3 \%)$ & $13(22.0 \%)$ & $1(16.7 \%)$ \\
\hline III & $47(26.6 \%)$ & $31(27.7 \%)$ & $15(25.4 \%)$ & $1(16.7 \%)$ \\
\hline IV & $32(18.1 \%)$ & $19(17.0 \%)$ & $11(18.6 \%)$ & $2(33.3 \%)$ \\
\hline Preoperative EF (\%) & $59.9 \pm 8.8(30-80)$ & $59.9 \pm 9.1(39-80)$ & $59.8 \pm 8.5(30-78)$ & $61.2 \pm 6.7(50-70)$ \\
\hline \multicolumn{5}{|l|}{ LV diameters } \\
\hline LVEDD $(\mathrm{mm})$ & $60.2 \pm 10.2(40-89)$ & $60.0 \pm 10.4(41-89)$ & $60.7 \pm 10.2(40-80)$ & $56.5 \pm 8.3(42-67)$ \\
\hline LVESD (mm) & $38.4 \pm 9.4(17-63)$ & $39.1 \pm 9.9(17-63)$ & $37.4 \pm 8.7(20-51)$ & $35.7 \pm 6.9(25-40)$ \\
\hline $\begin{array}{l}\text { Aortic annulus diameter (mm, on } \\
\text { preoperative TTE) }\end{array}$ & $26.7 \pm 3.4$ & $26.1 \pm 2.7$ & $27.6 \pm 4.2$ & $27.3 \pm 2.8$ \\
\hline $\begin{array}{l}\text { Sinuses of Valsalva (mm, on preoperative } \\
\text { TTE) }\end{array}$ & $50.2 \pm 7.9$ & $52.5 \pm 8.6$ & $46.7 \pm 4.9$ & $45.4 \pm 3.4$ \\
\hline $\begin{array}{l}\text { Aortic annulus diameter (Hegar, mm) } \\
\quad \mathrm{m} \pm \mathrm{SD} \text { (range) }\end{array}$ & $28.3 \pm 3.2(24-56)$ & $27.9 \pm 3.2(24-56)$ & $29.2 \pm 3.1(25-45)$ & $28.7 \pm 2.3(27-33)$ \\
\hline Aorta graft size $\mathrm{m} \pm \mathrm{SD}$ (range) & $28.0 \pm 1.7(24-34)$ & $27.6 \pm 1.5(24-32)$ & $28.6 \pm 1.7(26-34)$ & $28.3 \pm 0.8(28-30)$ \\
\hline 24 & $5(2.8 \%)$ & $5(4.5 \%)$ & - & - \\
\hline 26 & $39(22 \%)$ & $29(25.9 \%)$ & $10(16.9 \%)$ & - \\
\hline 28 & $92(52 \%)$ & $60(53.6 \%)$ & $27(45.8 \%)$ & $5(83.3 \%)$ \\
\hline 30 & $36(20.3 \%)$ & $17(15.2 \%)$ & $18(30.5 \%)$ & $1(16.7 \%)$ \\
\hline 32 & $4(2.3 \%)$ & $1(0.9 \%)$ & $3(5.1 \%)$ & - \\
\hline 34 & $1(0.6 \%)$ & - & $1(1.7 \%)$ & - \\
\hline Cusp repair $(\%)$ & $122(68.9 \%)$ & $57(50.9 \%)$ & $59(100.0 \%)$ & $6(100.0 \%)$ \\
\hline Central plicating stitches & $108(61.0 \%)$ & $53(47.3 \%)$ & $51(86.4 \%)$ & $4(66.7 \%)$ \\
\hline Pericardial patch & $5(2.8 \%)$ & $3(2.7 \%)$ & $1(1.7 \%)$ & $1(16.7 \%)$ \\
\hline Decalcification & $10(5.6 \%)$ & $3(2.7 \%)$ & $6(10.2 \%)$ & $1(16.7 \%)$ \\
\hline Cusp resection & $18(10.2 \%)$ & $2(1.8 \%)$ & $16(27.1 \%)$ & - \\
\hline Running suture & $1(0.6 \%)$ & $1(0.9 \%)$ & - & - \\
\hline \multirow[t]{3}{*}{ Annuloplasty ring diameter (mm) } & $26.9 \pm 1.6(24-32)$ & $26.7 \pm 1.5(24-30)$ & $27.3 \pm 1.8(25-32)$ & $26.8 \pm 1.6(25-29)$ \\
\hline & $6(3.4 \%)$ & $6(5.4 \%)$ & - & - \\
\hline & $37(20.9 \%)$ & $21(18.8 \%)$ & $14(23.7 \%)$ & $2(33.3 \%)$ \\
\hline 26 & $19(10.7 \%)$ & $18(16.1 \%)$ & $1(1.7 \%)$ & - \\
\hline 27 & $61(34.5 \%)$ & $33(29.5 \%)$ & $26(44.1 \%)$ & $2(33.3 \%)$ \\
\hline 28 & $27(15.3 \%)$ & $23(20.5 \%)$ & $3(5.1 \%)$ & $1(16.7 \%)$ \\
\hline 29 & $17(9.6 \%)$ & $7(6.3 \%)$ & $9(15.3 \%)$ & $1(16.7 \%)$ \\
\hline 30 & $6(3.4 \%)$ & $4(3.6 \%)$ & $2(3.4 \%)$ & - \\
\hline 31 & $2(1.1 \%)$ & - & $2(3.4 \%)$ & - \\
\hline 32 & $2(1.1 \%)$ & - & $2(3.4 \%)$ & - \\
\hline Other cardiac procedures & $39(22.0 \%)$ & $29(25.9 \%)$ & $9(15.3 \%)$ & $1(16.7 \%)$ \\
\hline CABG & $6(3.4 \%)$ & $5(5.4 \%)$ & $1(1.7 \%)$ & - \\
\hline
\end{tabular}


TABLE 1. Continued

\begin{tabular}{|c|c|c|c|c|}
\hline & Total & Tricuspid & Bicuspid & Unicuspid \\
\hline Mitral valve surgery & $10(5.6 \%)$ & $8(7.1 \%)$ & $2(3.4 \%)$ & - \\
\hline Arch replacement & $6(3.4 \%)$ & $5(5.4 \%)$ & - & $1(16.7 \%)$ \\
\hline PFO closure & $13(7.3 \%)$ & $9(8.0 \%)$ & $4(6.8 \%)$ & - \\
\hline AF surgery & $5(2.8 \%)$ & $4(3.6 \%)$ & $1(1.7 \%)$ & - \\
\hline AC time (min) mean $\pm \mathrm{SD}$ (range) & $145 \pm 30(81-244)$ & $142 \pm 31(81-244)$ & $151 \pm 28(85-235)$ & $146 \pm 25(114-188)$ \\
\hline Second CPB run & $8(4.5 \%)$ & $8(7.1 \%)$ & - & - \\
\hline \multicolumn{5}{|l|}{ Second CPB run: reason } \\
\hline Residual AI grade $\geq 2$ & 6 & 6 & - & - \\
\hline Bleeding & 1 & 1 & - & - \\
\hline Other & 1 & 1 & - & - \\
\hline \multicolumn{5}{|l|}{ Second CPB run: outcome } \\
\hline Re-repair & 6 & 6 & - & - \\
\hline Aortic valve replacement & 2 & 2 & - & - \\
\hline \multicolumn{5}{|l|}{ TTE at discharge } \\
\hline Grade 0 & $118(70.2 \%)$ & $72(67.9 \%)$ & $41(73.2 \%)$ & $5(83.3 \%)$ \\
\hline 1 & $49(29.2 \%)$ & $33(31.1 \%)$ & $15(26.8 \%)$ & $1(16.7 \%)$ \\
\hline $\begin{array}{l}\text { Aortic annulus diameter (mm, on TTE at } \\
\text { discharge) }\end{array}$ & $22.0 \pm 2.3$ & $22.1 \pm 2.5$ & $21.9 \pm 1.8$ & $21.4 \pm 1.4$ \\
\hline
\end{tabular}

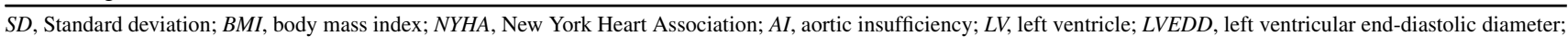
$L V E S D$, left ventricular end-systolic diameter; $T T E$, transthoracic echocardiogram; $C A B G$, coronary artery bypass grafting; $P F O$, patent foramen ovale; $A F$, atrial fibrillation; $A C$, aortic crossclamping; $C P B$, cardiopulmonary bypass.

as valve-related deaths, permanent pacemaker, and valve-related morbidity (structural and nonstructural valve dysfunction, thromboembolic, hemorrhagic, or endocarditis events). ${ }^{24}$ We also focused on analyses of bicuspid versus tricuspid valves and time periods, before and after 2007, corresponding to the introduction of the calibrated Extra-Aortic ring annuloplasty followed 1 year later by the systematic assessment of cusp effective height.

\section{Statistical Methodology}

Results were expressed as frequencies and percentages for qualitative data and as mean \pm standard deviation or as median with its interquartile range (first quartile to third quartile) for continuous data. Paired $t$ test was used to compare preoperative and postoperative values of the transvalvular aortic gradient. Freedom from reoperation, AI recurrence, and MAVRE were displayed graphically using Kaplan-Meier graphs, and the influence of key independent variables was assessed using the log-rank test. Univariate Cox models were used to estimate the hazard ratios (HRs) associated with preoperative and intraoperative independent variables and their influence on freedom from reoperation and AI recurrence. All tests were 2 sided. All computations were done using SPSS v13 statistical software (SPSS Inc, Chicago, Ill).

\section{RESULTS \\ Early Outcomes}

Thirty-day mortality was $2.9 \%$ (5). The causes of death were pulmonary embolism (1), mesenteric ischemia (2), multiorgan failure (1), and cardiogenic shock (1). None were valve related. There was no operative mortality in those with Marfan syndrome. Thromboembolic events occurred in 5 patients ( 2 transient ischemic attacks, 3 strokes).

Mean aortic annulus diameter was dilated $(>25 \mathrm{~mm})$ in all patients. Cusp repair was necessary in $68.9 \%$ of patients, performed mostly through central plicating stitches (Table 1).

Six patients $(3.4 \%)$ required second cardiopulmonary bypass run for residual AI grade 2 or greater because of residual prolapse. The valve could be repaired in 4 cases; 2 patients underwent valve replacement (Table 1).

An 18-year-old patient with Marfan syndrome developed proximal false aortic aneurysm induced by a tear from the pledgeted anchoring stitch of the aortic ring (nonstructural valve deterioration). Entry of the false aneurysm was closed from inside the left ventricular outflow tract 2 weeks after initial operation. The ring was in the correct position, and another U-stitch was placed to fix it. Another patient underwent early reoperation on the first postoperative day for ventricular fibrillation due to plication of the left main trunk, which was repositioned successfully under cardiopulmonary bypass. In both cases, no abnormalities of the ring or the repaired aortic valve were noted. Patients recovered uneventfully. Three patients ( 1 with bicuspid valve and 2 with tricuspid valves) required a permanent pacemaker for atrioventricular block within 30 days postoperatively $(1.7 \%)$. Reoperation for bleeding or pericardial effusion was needed in 4 patients $(2.3 \%)$ and for mediastinitis in 1 patient.

\section{Late Outcomes}

Follow-up was extensive with all patients being followed clinically and echocardiographically every 2 years in our center (respective $\mathrm{C}$ statistic of 0.74 and 0.78 ) and with their local cardiologist every year. ${ }^{25}$ Cumulative patient followup was 599.28 patient-years (mean, $41.1 \pm 36.4$ months). 


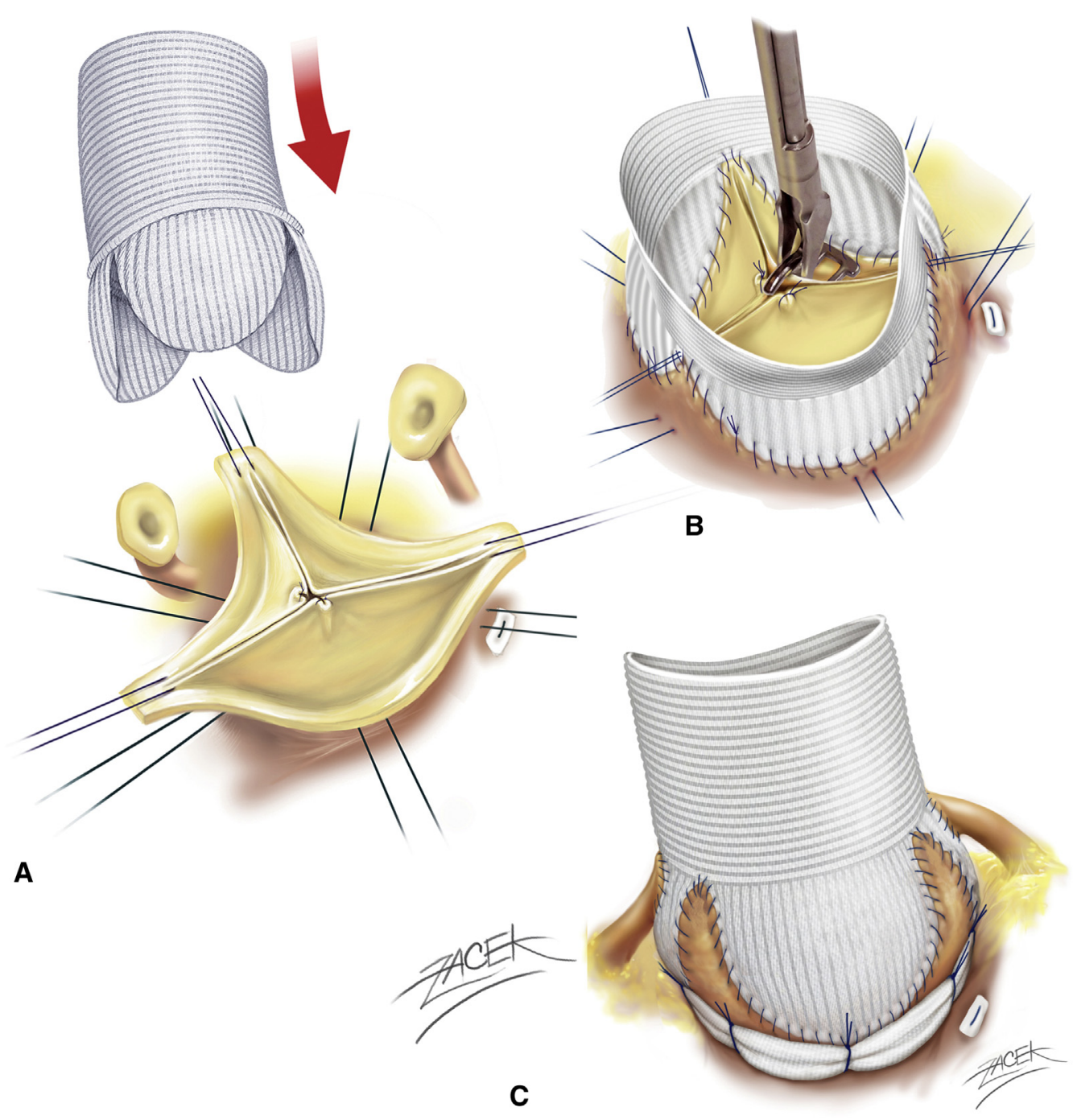

FIGURE 1. Standardized steps in remodeling of the aortic root associated with cusp effective height resuspension and external expansible subvalvular aortic ring annuloplasty: A, Five "U" stitches are circumferentially placed, inside out, in the subvalvular plane except at the level of the commissure between the noncoronary and right coronary sinuses where a sixth stitch is placed externally to avoid damage to the membranous septum. Remodeling of the aortic root is then performed by scalloping a bulged graft. B, Measure of cusp effective height with the caliper. C, The anchoring "U" stitches are passed through the inner aspect of the prosthetic aortic ring and tied down externally in the subvalvular position.

Actuarial survival was $92.7 \% \pm 2.2 \%$ at 7 years. There were 4 sudden deaths, 2 cardiac nonvalvular-related deaths, and 2 noncardiac deaths.

Freedom from valve-related reoperation, AI grade 3 or greater, AI grade 2 or greater, and MAVRE was $89.5 \%$, $90.5 \%, 77.4 \%$, and $86.6 \%$, respectively, at 7 years. Eight patients underwent a valve-related reoperation for structural valve deterioration at a mean of 59 months postoperatively (25-125). All patients had a tricuspid valve and underwent operation with a Dacron ring before 2007. None of the patients with bicuspid aortic valves underwent reoperation during follow-up. At 7 years follow-up, freedom from thromboembolic events was $98.8 \%$.

There were no differences between bicuspid and tricuspid valve outcomes (Figures 2 and 3). Freedom from reoperation at 7 years for bicuspid valve was $100 \%$ versus $88.8 \%$ for tricuspid valves, $100 \%$ versus $89.6 \%$ for freedom from AI grade 3 or greater, $68.7 \%$ versus $81.6 \%$ for freedom from AI grade 2 or greater, and $98.2 \%$ versus $81.7 \%$ for freedom from MAVRE.

\section{Period and Protector Factor Analysis}

Since 2007, systematic use of a dedicated expansible ring annuloplasty (Extra-Aortic) followed 1 year later by systematic cusp effective height assessment was significantly associated with an increased 7-year freedom from valve-related reoperation, AI grade 3 or greater, and MAVRE up to $99.1 \% \pm 0.9 \%(P=.017), 100 \%(P=.026)$, and $96.3 \% \pm 1.8 \%(P=.035)$, respectively, whereas 
TABLE 2. Criteria for choice of the aortic ring and tube graft diameters

\begin{tabular}{lccccc}
\hline & \multicolumn{5}{c}{ Aortic annular base } \\
& \multicolumn{5}{c}{ diameter (Hegar dilators, mm) } \\
\cline { 2 - 6 } & $\mathbf{2 5 - 2 7}$ & $\mathbf{2 8 - 3 0}$ & $\mathbf{3 1 - 3 3}$ & $\mathbf{3 4 - 3 9}$ & $>\mathbf{4 0}$ \\
\hline $\begin{array}{l}\text { Valsalva tube graft diameter } \\
(\mathrm{mm})\end{array}$ & 26 & 28 & 30 & 32 & 34 \\
$\begin{array}{l}\text { Extra-Aortic ring } \\
\text { annuloplasty diameter } \\
(\mathrm{mm})\end{array}$ & 25 & 27 & 29 & 31 & 33 \\
\hline
\end{tabular}

freedom from AI grade 2 or greater remained unaffected $(78.1 \% \pm 7.6 \%)$.

Since 2007, the systematic use of calibrated expansible aortic ring annuloplasty (Extra-Aortic) was significantly protective from recurrence of AI grade 3 or greater (no AI grade $\geq 3$ events, $P=.026$ ), reoperation (HR, $0.11 ; 95 \%$ confidence interval [CI], 0.01-0.95; $P=.044)$, and MAVRE (HR, 0.29; 95\% CI, 0.09-0.98; $P=.046$ ) when compared with the homemade Dacron ring (Table 3 and Figures 4 and 5).

Since 2008, systematic cusp effective height assessment was associated with an increased rate of valve repair from $32.9 \%$ to $96.2 \%(P<.001)$ and was significantly protective from AI grade 3 or greater (no AI grade $\geq 3$ events, $P=.043$ ), reoperation (HR, 0.13; 95\% CI, 0.02-1.06; $P=.057$ ), and MAVRE (HR, 0.20; 95\% CI, 0.05-0.76; $P=.018$ ) (Table 3) when compared with "eyeballing repair."

Preoperative AI grade was the only predictor for recurrence of AI 2 or greater (HR, 1.66; 95\% CI, 1.10-2.51;

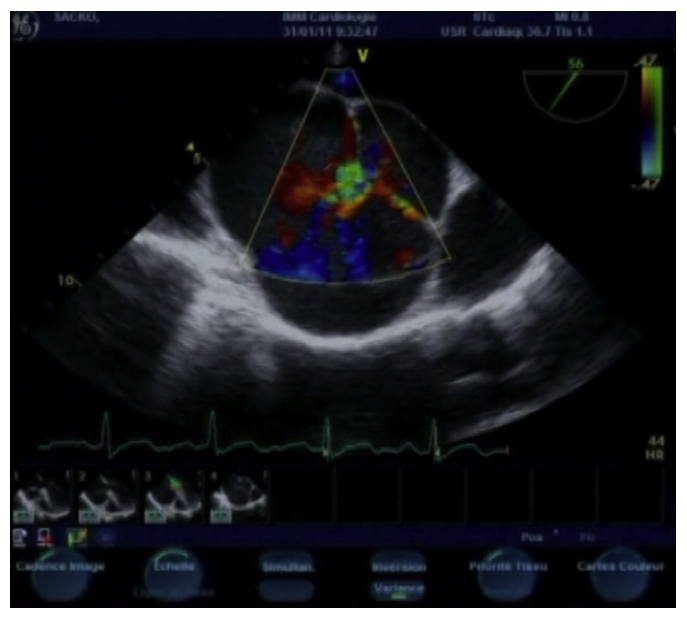

VIDEO 1. Remodeling root repair with expansible aortic ring annuloplasty for tricuspid valve. Standardized steps in remodeling root repair associated with cusp effective height resuspension and external expansible aortic ring annuloplasty to treat an aortic root aneurysm associated with grade III eccentric AI with tricuspid aortic valves. Video available at: http://www.jtcvsonline.org/article/S0022-5223(17)30015-6/addons.

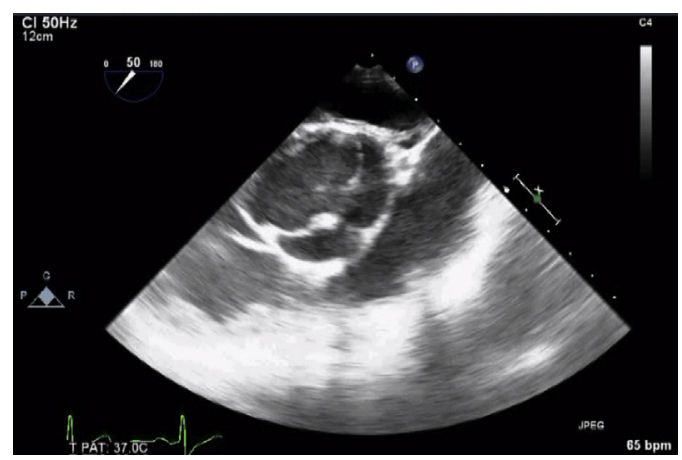

VIDEO 2. Remodeling root repair with expansible aortic ring annuloplasty for bicuspid valve. Standardized steps in remodeling root repair associated with cusp effective height resuspension and external expansible aortic ring annuloplasty to treat an aortic root aneurysm associated with grade III eccentric AI with bicuspid aortic valves. Video available at: http://www.jtcvsonline.org/article/S0022-5223(17)30015-6/addons.

$P=.016)$ (Table 3). Cusp repair, type of valve, preoperative aortic annulus, and sinus of Valsalva diameters had no influence on reoperation risk.
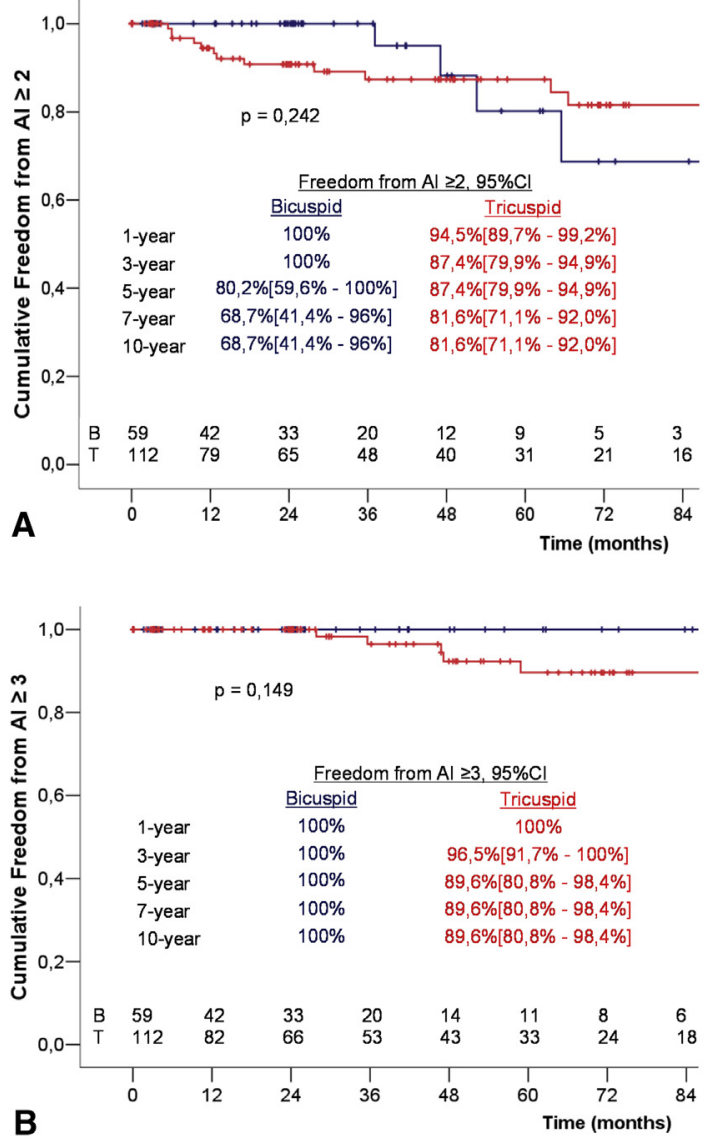

FIGURE 2. Kaplan-Meier analysis of freedom from AI grade 2 or greater (A) and AI grade 3 or greater (B) for bicuspid and tricuspid valves. AI, Aortic insufficiency; $C I$, confidence interval; $B$, bicuspid; $T$, tricuspid. 

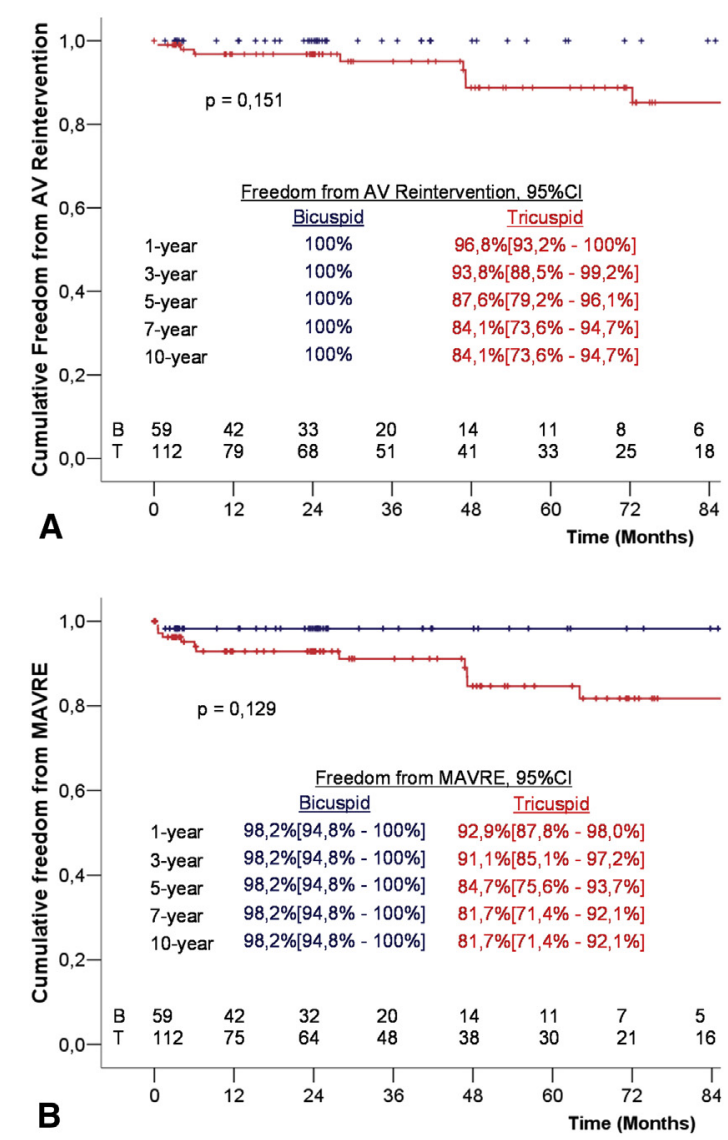

FIGURE 3. Kaplan-Meier analysis of freedom from aortic valve reoperation (A) and from MAVRE (B) for bicuspid and tricuspid valves. $A V$, Aortic valve; $C I$, confidence interval; $B$, Bicuspid; $T$, tricuspid; MAVRE, major adverse valve-related events.
The aortic ring significantly reduced the native aortic annulus diameter by $-4.3 \pm 3.9 \mathrm{~mm}(-15.2 \% \pm 12.5 \%$, $P<.001)$, thus providing a satisfactory coaptation height of $8.4 \pm 2.2 \mathrm{~mm}$ and a $10.2 \pm 3.3 \mathrm{~mm}$ effective height. At the latest follow-up, the amount of annular reduction compared with its postoperative values was still preserved. The mean transvalvular gradient measured postoperatively was similar for bicuspid and tricuspid morphologies (7.2 $\pm 2.7 \mathrm{~mm} \mathrm{Hg}$ and $6.8 \pm 2.8 \mathrm{~mm} \mathrm{Hg}$, respectively) and remained stable over time.

Systolic/diastolic expansibility of the aortic annulus after expansible aortic annuloplasty was maintained postoperatively and at follow-up, $4.0 \% \pm 8.3 \%$ and $4.1 \% \pm 6.1 \%$, respectively, when compared with the preoperative value of native annulus $(3.5 \% \pm 9.6 \%)$. Expansibility of the sinuses of Valsalva was preserved, $3.8 \% \pm 14 \%$ postoperatively and $2.1 \% \pm 5.3 \%$ at last follow-up, respectively, for a native expansibility of $1.5 \% \pm 11.9 \%$.

\section{DISCUSSION}

Although the remodeling technique provides the most physiologic valve-sparing root replacement compared with the reimplantation technique, a dilated aortic annulus $(>25 \mathrm{~mm})$ is a risk factor for failure. ${ }^{2-8}$ External aortic ring annuloplasty associated with the remodeling technique efficiently addresses this issue by reducing the dilated aortic annulus $(-5 \mathrm{~mm})$, which increases the coaptation height, thus protecting the repair while sustaining valve stability at 7 years. ${ }^{16,18}$ These results are consistent with recent publications showing that the

TABLE 3. Influence of different parameters on late outcomes

\begin{tabular}{|c|c|c|c|c|c|c|c|c|}
\hline \multirow{2}{*}{$\frac{\text { Outcome }}{\text { Factor }}$} & \multicolumn{2}{|c|}{ Freedom from $\mathrm{AI} \geq 2$} & \multicolumn{2}{|c|}{ Freedom from $A I \geq 3$} & \multicolumn{2}{|c|}{ AV reintervention } & \multicolumn{2}{|c|}{ MAVRE } \\
\hline & HR, 95\% CI & $P$ value & HR, 95\% CI & $P$ value & HR, 95\% CI & $P$ value & HR, $95 \%$ CI & $P$ value \\
\hline $\begin{array}{l}\text { Cusp effective height } \\
\text { assessment }\end{array}$ & $0.96(0.37-2.50)$ & .939 & $-\dagger$ & .043 & $0.13(0.02-1.06)$ & .057 & $0.20(0.05-0.76)$ & .018 \\
\hline Cusp repair & $1.23(0.47-3.25)$ & .676 & $0.46(0.08-2.53)$ & .374 & $0.43(0.10-1.84)$ & .257 & $0.52(0.17-1.57)$ & .243 \\
\hline $\begin{array}{c}\text { Extra-Aortic ring (Extra- } \\
\text { Aortic, CORONEO, Inc, } \\
\text { Montreal, QC, Canada) }\end{array}$ & $1.5(0.57-3.96)$ & .414 & $-\dagger$ & .026 & $0.11(0.01-0.95)$ & .044 & $0.29(0.09-0.98)$ & .046 \\
\hline Leaflet anatomy & & .281 & $\dagger$ & .149 & & .151 & & .262 \\
\hline Tricuspid & Reference & - & Reference & - & Reference & - & Reference & - \\
\hline Bicuspid & $0.82(0.26-2.57)$ & .737 & $-\dagger$ & & $-\dagger$ & & $0.18(0.02-1.4)$ & .102 \\
\hline Unicuspid & $3.07(0.68-13.75)$ & .143 & $3.37(0.39-28.9)$ & .267 & $-\dagger$ & & 0 & .983 \\
\hline Preoperative AI* & $1.66(1.1-2.51)$ & .016 & $1.63(0.78-3.44)$ & .196 & $0.94(0.53-1.65)$ & .824 & $0.98(0.64-1.5)$ & .939 \\
\hline $\begin{array}{c}\text { Intraoperative Aortic } \\
\text { annulus diameter }\end{array}$ & $1.02(0.91-1.15)$ & .693 & $0.84(0.51-1.38)$ & .493 & $0.88(0.59-1.3)$ & .516 & $0.85(0.62-1.16)$ & .303 \\
\hline Valsalva diameter & $0.99(0.94-1.05)$ & .853 & $1.00(0.92-1.09)$ & .987 & $1.03(0.98-1.09)$ & .268 & $1.02(0.97-1.07)$ & .527 \\
\hline STJ diameter & $1.03(0.99-1.08)$ & .122 & $1.01(0.93-1.1)$ & .778 & $1.01(0.93-1.09)$ & .883 & $1.01(0.95-1.07)$ & .676 \\
\hline Preoperative LVEF & $0.97(0.93-1.02)$ & .248 & $1.04(0.93-1.16)$ & .462 & $1.04(0.94-1.15)$ & .461 & $1.09(1.00-1.18)$ & .042 \\
\hline
\end{tabular}

$A I$, Aortic insufficiency; $A V$, aortic valve; $M A V R E$, major adverse valve-related events; $H R$, hazard ratio; $C I$, confidence interval; $S T J$, sinotubular junction; $L V E F$, left ventricular ejection fraction. ${ }^{*} \mathrm{HR}$ for 1 grade incremental in preoperative AI. $\dagger$ No HR can be estimated because this group had no AI of 3 or greater. The corresponding $P$ value is derived from the log-rank test (Kaplan-Meier), not the Cox model, because it did not converge. 

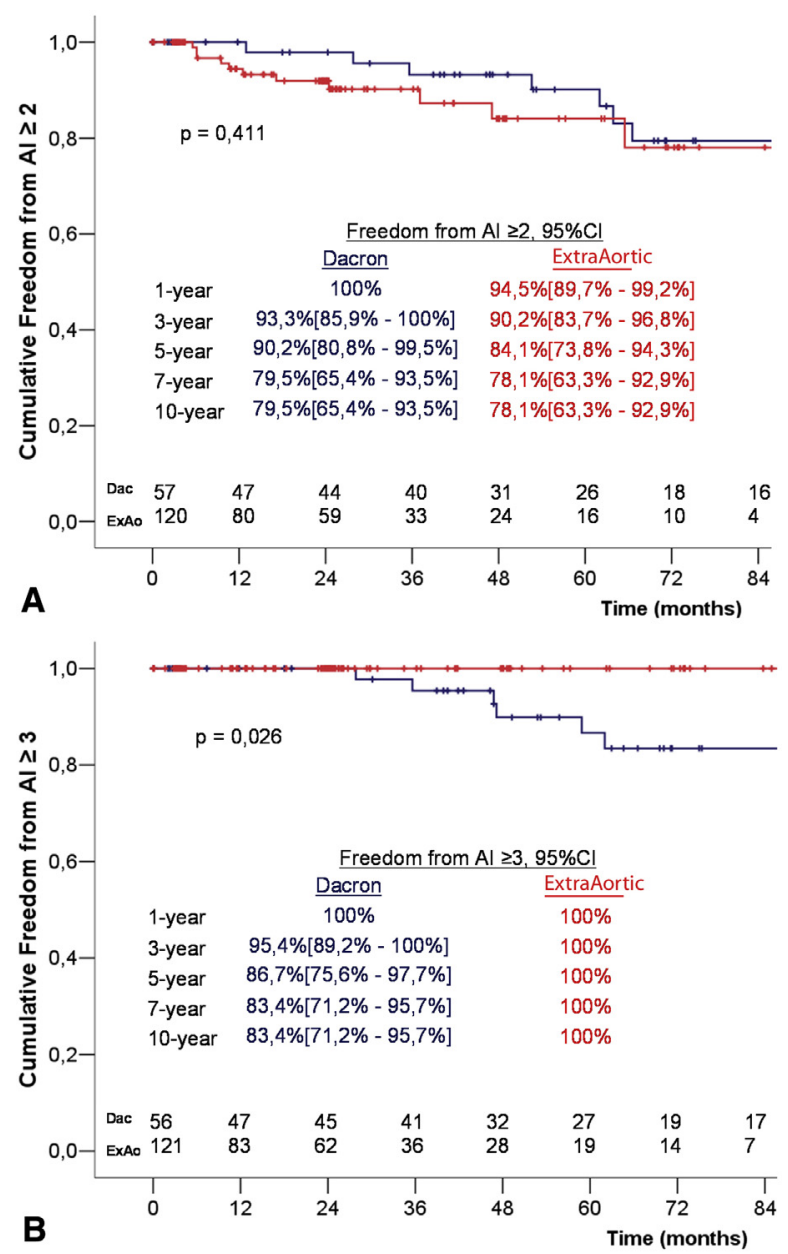

FIGURE 4. Kaplan-Meier analysis of freedom from AI grade 2 or greater (A) and AI grade 3 or greater (B) before 2007 using the Dacron ring and eyeballing repair (Dac, Eh-) and after 2007 with systematic use of calibrated expansible ring annuloplasty, followed 1 year later by systematic cusp effective height assessment (ExAo, Eh+). AI, Aortic insufficiency; $C I$, confidence interval.

reimplantation technique provides more significant and durable annular reduction than subcommissural annular stiches, thus corroborating that the proximal suture of a reimplantation technique not only stabilizes the aortic annulus but also performs an aortic annuloplasty. ${ }^{26-28}$ Furthermore, this study emphasizes that a calibrated expansible aortic ring annuloplasty (ie, downsizing annuloplasty as described in "Materials and Methods") is significantly protective from reoperation, recurrent AI grade 3 or greater, and MAVRE when compared with a homemade Dacron ring, as was used in our early experience. It is tightly bound with the protective effect of cusp effective height assessment when compared with subjective eye balling repair, as previously published in a multicentric series. ${ }^{18}$ Likewise, Schäfers and colleagues ${ }^{6}$ showed that addition of a circumferential annuloplasty to
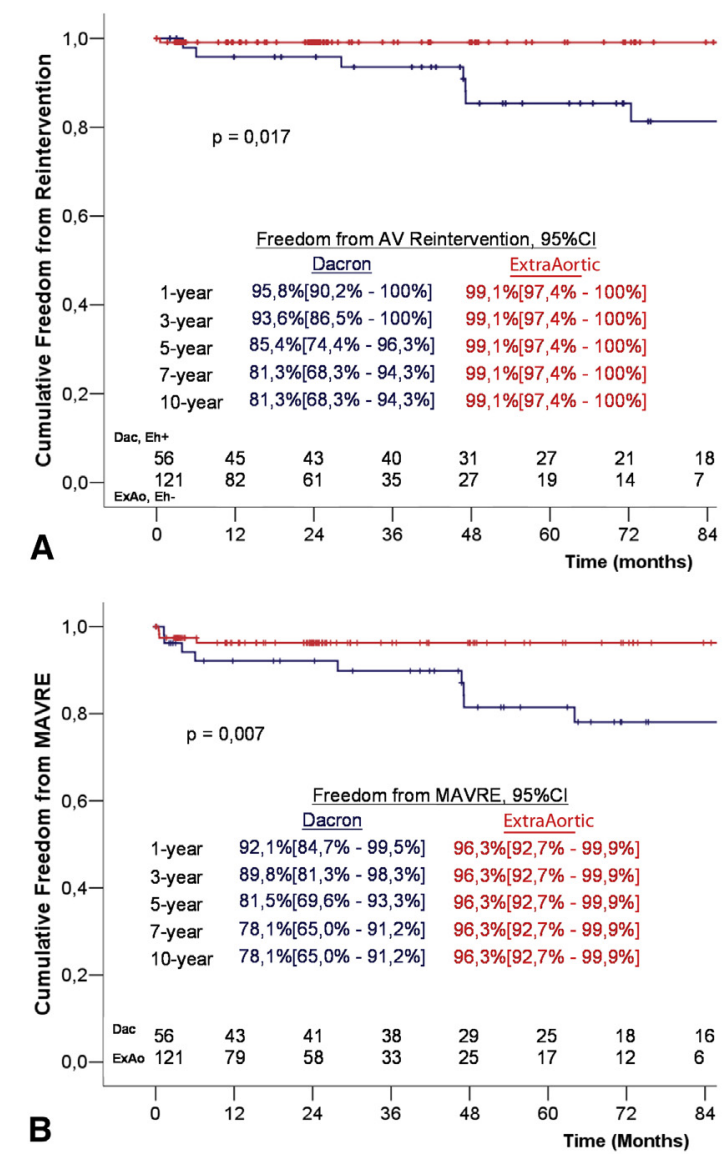

FIGURE 5. Kaplan-Meier analysis of freedom from aortic valve reoperation (A) and from MAVRE (B) by time period before 2007 using the Dacron ring and eyeballing repair (Dac, Eh-) and after 2007 with systematic use of calibrated expansible ring annuloplasty, followed 1 year later by systematic cusp effective height assessment (ExAo, Eh+). AV, Aortic valve; $C I$, confidence interval; $M A V R E$, major adverse valve-related events.

the cusp effective height resuspension induced a trend to reduction of the risk of reoperation in bicuspid isolated aortic valve repair and significantly reduced the incidence of residual $\mathrm{AI}$ in combination with a remodeling root repair. $^{5}$

Aside from numerous in vivo and in vitro studies showing more physiologic movements of the valve after remodeling of the aortic root relative to reimplantation of the aortic valve, our choice to combine "remodeling + ring" over reimplantation also is related to standardization. ${ }^{8,16-18}$ The remodeling root reconstruction performed in this study with the Valsalva graft places the commissure at the same level and symmetrically at $120^{\circ}$ for a tricuspid valve and $180^{\circ}$ for a bicuspid valve. Effective height resuspension using Schäfers' caliper is then performed allowing correct placement of the caliper at the nadir of the cusp on an unconstrained aortic annulus. The external ring annuloplasty is performed at the end of the procedure, contrary to the reimplantation technique that starts the 
procedure with the annuloplasty through the proximal suture line, making valve assessment more challenging because the valve is constrained by the graft.

This study confirms our previous findings ${ }^{19}$ that systolic expansibility is maintained both postoperatively and during follow-up with the expansible aortic ring annuloplasty (Extra-Aortic), which may improve valve repair durability, as also described recently by Basmadjian and colleagues. ${ }^{29}$ No patients with bicuspid valves required reoperation, with satisfactory results maintained over time comparable to tricuspid valves.

Of note, the preoperative degree of AI was identified as a risk factor for postoperative AI grade 2 or greater, but not for AI grade 3 or greater or reoperation (Table 3). Metaanalysis of residual or recurrent $\mathrm{AI}$ is difficult to carry out because some authors report AI on a scale of 3 graduations (mild, moderate, severe), and others report on a scale of 4 grades (1-4). The major drawback of reporting with only 3 grades is the invisibility of "mild-to-moderate" AI (equivalent to AI grade 2), which are included in the "mild" group. ${ }^{30,31}$ Patients with AI grade 2 should be followed up and analyzed on a larger scale to determine which criterion will lead to increased AI (to grade $\geq 3$ ) and to reoperation. Furthermore, as recently mentioned in a systematic review of valve-sparing root replacement series, report of valve-related events is heterogeneous, emphasizing the need for uniform standardized reporting of aortic valve-sparing and repair procedures and their outcomes. ${ }^{21}$ To encourage collaboration between centers in their reporting of aortic valve-sparing and repair procedures, the Heart Valve Society initiated the multicenter, prospective AVIATOR, which is open to all centers willing to participate (AorticValve repair InternATiOnal Registry, E-mail: aviator@heartvalvesociety.org). ${ }^{21}$

\section{Study Limitations}

This is an observational uncontrolled study. The low number of events during follow-up limited further statistical analysis. Both the Extra-Aortic annuloplasty ring and the cusp effective height assessment have been found to be protective factors of AI recurrence. Because the time interval separating the implementation of the 2 techniques is less than 1 year, it would have been interesting to assess whether those patients undergoing operation during this time interval would have had similar results as those managed by both techniques. However, there have been few events or recurrences in this subset of patients, so any meaningful statistical analysis is impossible. From the clinical standpoint, the combination of the 2 techniques into a standardized approach is currently routine in our practice and yielding reproducibly sustainable 7-year results. Moreover, learning curve and operator experience may have a confounding influence on results of patients undergoing operation in the early experience. Longer follow-up of a larger cohort is required to understand whether our adopted paradigm translates into longer valve durability and improved clinical results.

\section{CONCLUSIONS}

The standardization of remodeling root repair with calibrated expansible aortic ring annuloplasty and cusp effective height resuspension significantly improves valve repair outcomes at 7 years. Because repair of bicuspid valves provides stable results, similar to tricuspid valves, it may be primarily proposed to treat root aneurysms with pliable bicuspid valves. As was the case for mitral repair, standardization through a calibrated annuloplasty may increase the rate of aortic valve repair for both tricuspid and bicuspid valves, even in patients with severe AI. Multicentric, longer follow-up is ongoing with the AVIATOR.

\section{Conflict of Interest Statement}

E.L. has consultant agreements with CORONEO, Inc (www.coroneo.com), in connection with the development of an aortic ring bearing the trade name "Extra-Aortic." All other authors have nothing to disclose with regard to commercial support.

The authors thank the Assistance Publique Hopitaux de Paris, especially Dr Cécile Hoffart-Jourdain from the Departmental Direction of the Clinical Research, as well as Florence Tubach, Estelle Marcault, and Naima Beldjoudi from the Unit of Clinical Research Paris-Nord for continuous support in building and realizing this study.

\section{References}

1. Erbel R, Aboyans V, Boileau C, Bossone E, Bartolomeo RD, Eggebrecht H, et al. 2014 ESC Guidelines on the diagnosis and treatment of aortic diseases: document covering acute and chronic aortic diseases of the thoracic and abdominal aorta of the adult. The Task Force for the Diagnosis and Treatment of Aortic Diseases of the European Society of Cardiology (ESC). Eur Heart J. 2014;35 2873-926.

2. Soncini M, Votta E, Zinicchino S, Burrone V, Mangini A, Lemma M, et al. Aortic root performance after valve sparing procedure: a comparative finite element analysis. Med Eng Phys. 2009;31:234-43.

3. Luciani GB, Casali G, Tomezzoli A, Mazzucco A. Recurrence of aortic insufficiency after aortic root remodeling with valve preservation. Ann Thorac Surg. 1999;67:1849-52.

4. Hanke T, Charitos EI, Stierle U, Robinson D, Gorski A, Sievers HH, et al. Factors associated with the development of aortic valve regurgitation over time after two different techniques of valve-sparing aortic root surgery. J Thorac Cardiovasc Surg. 2009;137:314-9.

5. Aicher D, Schneider U, Schmied W, Kunihara T, Tochii M, Schäfers HJ. Early results with annular support in reconstruction of the bicuspid aortic valve. $J$ Thorac Cardiovasc Surg. 2013;145:S30-4.

6. Schäfers HJ, Raddatz A, Schmied W, Takahashi H, Miura Y, Kunihara T, et al Reexamining remodeling. J Thorac Cardiovasc Surg. 2015;149(2 Suppl):S30-6.

7. Kunihara T, Aicher D, Rodionycheva S, Groesdonk HV, Langer F, Sata F, et al Preoperative aortic root geometry and postoperative cusp configuration primarily determine long-term outcome after valve-preserving aortic root repair. $J$ Thorac Cardiovasc Surg. 2012;143:1389-95.

8. Lansac E, Di Centa I, Bonnet N, Leprince P, Jault F, Rama A, et al. Aortic prosthetic ring annuloplasty: a useful adjunct to a standardized aortic valve-sparing procedure? Eur J Cardiothorac Surg. 2006;29:537-44.

9. Leyh RG, Schmidtke C, Sievers HH, Yacoub MH. Opening and closing characteristics of the aortic valve after different types of valve-preserving surgery. Circulation. 1999;100:2153-60. 
10. De Paulis R, De Matteis GM, Nardi P, Scaffa R, Bassano C, Chiariello L. Analysis of valve motion after the reimplantation type of valve-sparing procedure (David I) with a new aortic root conduit. Ann Thorac Surg. 2002;74:53-7.

11. Marom G, Haj-Ali R, Rosenfeld M, Schäfers HJ, Raanani E. Aortic root numeric model: annulus diameter prediction of effective height and coaptation in postaortic valve repair. J Thorac Cardiovasc Surg. 2013;145:406-11.

12. le Polain de Waroux JB, Pouleur AC, Robert A, Pasquet A, Gerber BL, Noirhomme P, et al. Mechanisms of recurrent aortic regurgitation after aortic valve repair: predictive value of intraoperative transesophageal echocardiography. JACC Cardiovasc Imaging. 2009;2:931-9.

13. Detain D, Jondeau G. Dystrophic aortic insufficiency. Rev Prat. 2009;59:187-93.

14. Gaudino M, Lau C, Munjal M, Avgerinos D, Girardi LN. Contemporary outcomes of surgery for aortic root aneurysms: a propensity-matched comparison of valve-sparing and composite valve graft replacement. J Thorac Cardiovasc Surg. 2015;150:1120-9.

15. Stamou SC, Williams ML, Gunn TM, Hagberg RC, Lobdell KW, Kouchoukos NT. Aortic root surgery in the United States: a report from the Society of Thoracic Surgeons database. J Thorac Cardiovasc Surg. 2015;149: 116-22.e4.

16. Lansac E, Bouchot O, Arnaud Crozat E, Hacini R, Doguet F, Demaria R, et al. Standardized approach to valve repair using an expansible aortic ring versus mechanical Bentall: early outcomes of the CAVIAAR multicentric prospective cohort study. J Thorac Cardiovasc Surg. 2015;149(2 Suppl):S37-45.

17. Lansac E, Di Centa I, Vojacek J, Nijs J, Hlubocky J, Mecozzi G, et al. Valve sparing root replacement: the remodeling technique with external ring annuloplasty. Ann Cardiothorac Surg. 2013;2:117-23.

18. Lansac E, Di Centa I, Sleilaty G, Arnaud Crozat E, Bouchot O, Hacini R, et al. An aortic ring: from physiologic reconstruction of the root to a standardized approach for aortic valve repair. J Thorac Cardiovasc Surg. 2010;140:S28-35.

19. Lansac E, Di Centa I, Raoux F, Bulman-Fleming N, Ranga A, Abed A, et al. An expansible aortic ring for a physiological approach to conservative aortic valve surgery. J Thorac Cardiovasc Surg. 2009;138:718-24.

20. Wuliya M, Sleilaty G, Di Centa I, Khelil N, Berrebi A, Czitrom D, et al. An expansible aortic ring to preserve aortic root dynamics after aortic valve repair. Eur J Cardiothorac Surg. 2015;47:482-90.

21. Arabkhani B, Mookhoek A, Di Centa I, Lansac E, Bekkers JA, De Lind Van Wijngaarden R, et al. Reported outcome after valve-sparing aortic root replace- ment for aortic root aneurysm: a systematic review and meta-analysis. Ann Thorac Surg. 2015;100:1126-31.

22. Schäfers HJ, Schmied W, Marom G, Aicher D. Cusp height in aortic valves. J Thorac Cardiovasc Surg. 2013;146:269-74.

23. Schäfers HJ, Bierbach B, Aicher D. A new approach to the assessment of aortic cusp geometry. J Thorac Cardiovasc Surg. 2006;132:436-8.

24. Akins CW, Miller DC, Turina MI, Kouchoukos NT, Blackstone EH, Grunkemeier GL, et al. Guidelines for reporting mortality and morbidity after cardiac valve interventions. Eur J Cardiothorac Surg. 2008;33: 523-8.

25. Clark TG, Altman DG, De Stavola BL. Quantification of the completeness of follow-up. Lancet. 2002;359:1309-10.

26. de Kerchove L, Mastrobuoni S, Boodhwani M, Astarci P, Rubay J, Poncelet A, et al. The role of annular dimension and annuloplasty in tricuspid aortic valve repair. Eur J Cardiothorac Surg. 2016;49:428-37.

27. Navarra E, El Khoury G, Glineur D, Boodhwani M, Van Dyck M, Vanoverschelde JL, et al. Effect of annulus dimension and annuloplasty on bicuspid aortic valve repair. Eur J Cardiothorac Surg. 2013;44: 316-22.

28. Vallabhajosyula P, Komlo C, Szeto WY, Wallen TJ, Desai N, Bavaria JE. Root stabilization of the repaired bicuspid aortic valve: subcommissural annuloplasty versus root reimplantation. Ann Thorac Surg. 2014;97: 1227-34.

29. Basmadjian L, Basmadjian AJ, Stevens LM, Mongeon FP, Cartier R, Poirier N, et al. Early results of extra-aortic annuloplasty ring implantation on aortic annular dimensions. J Thorac Cardiovasc Surg. 2016;151: 1280-5.e1.

30. David TE, Feindel CM, David CM, Manlhiot C. A quarter of a century of experience with aortic valve-sparing operations. J Thorac Cardiovasc Surg. 2014;148 $872-9$.

31. De Paulis R, Chirichilli I, Scaffa R, Weltert L, Maselli D, Salica A, et al. Longterm results of the valve reimplantation technique using a graft with sinuses. $J$ Thorac Cardiovasc Surg. 2016;151:112-9.

Key Words: aortic annuloplasty, aortic ring, valve repair, effective height, valve sparing, remodeling 